\title{
Glucocorticoid inhibits cell proliferation in differentiating osteoblasts by microRNA-199a targeting of WNT signaling
}

\author{
Changgui Shi ${ }^{1,2, *}$, Ping Huang ${ }^{1, *}$, Hui Kang1, Bo Hu ${ }^{1,2}$, Jin Qi', Min Jiang', Hanbing Zhou', \\ Lei Guo' and Lianfu Deng' \\ ${ }^{1}$ Shanghai Key Laboratory for Bone and Joint Diseases, Shanghai Institute of Orthopaedics and Traumatology, \\ Shanghai Ruijin Hospital, Shanghai Jiaotong University School of Medicine, No.197, The Second Ruijin Road, \\ Luwan District, Shanghai 200025, People's Republic of China \\ ${ }^{2}$ Department of Orthopedics, Changzheng Hospital, The Second Military Medical University of China, \\ Shanghai, People's Republic of China \\ *(C Shi and P Huang contributed equally to this work)
}

Correspondence should be addressed to L Guo Email guolei607@126.com

\begin{abstract}
The inhibition of osteoblast proliferation by glucocorticoids (GCs) is very important in the etiology of GC-induced osteoporosis. The mechanisms of this process are still not fully understood. The results of recent studies have indicated an important role for microRNAs in GC-mediated responses in various cellular processes, including cell proliferation and apoptosis. Therefore, we developed the hypothesis that these regulatory molecules might be involved in GC-decreased osteoblast proliferation. Western blotting, quantitative realtime PCR, cell proliferation assays, and luciferase assays were employed to investigate the role of miRNAs in GC-inhibited osteoblast proliferation. microRNA-199a-5p was significantly increased in osteoblasts treated with dexamethasone (Dex). To delineate the role of microRNA-199a-5p, we silenced and overexpressed microRNA-199a-5p in osteoblasts. We found that overexpressing microRNA-199a-5p remarkably increased the inhibition effect of Dex on osteoblast proliferation, and depleting microRNA-199a-5p significantly attenuated Dex-inhibited osteoblast proliferation. Results of mechanistic studies indicated that microRNA-199a-5p inhibited FZD4 and WNT2 expression through a microRNA-199a-5p binding site within the $3^{\prime}$-UTR of FZD4 and WNT2. The post-transcriptional repression of FZD4 and WNT2 were further confirmed by luciferase reporter assay. These results indicated that microRNA-199a-5p may play a significant role in GC-inhibited osteoblast proliferation by regulating the WNT signaling pathway.
\end{abstract}
Key Words
- microRNA-199a-5p
- glucocorticoids
- WNT signaling
- osteoblasts
- proliferation

\author{
Journal of Molecular \\ Endocrinology \\ (2015) 54, 325-337
}

\section{Introduction}

Glucocorticoids (GCs) are widely used for the treatment of inflammatory and immune diseases, including asthma, rheumatoid arthritis, Crohn's disease, and so on (Tait et al. 2008, Shi et al. 2014a,b). Although GCs are used extensively to relieve these diseases, increased bone fragility attributed to osteopenia is a serious side effect of prolonged 
GC administration (Kondo et al. 2008). Indeed, GC-induced osteoporosis (GIO) is currently the third leading cause of osteoporosis, following sex-steroid deficiency and old age (Weinstein et al. 1998). GC-treated patients are at a twofold higher risk of suffering from a fracture, irrespective of their bone mineral density (Weinstein 2001). Limited information is available on the pathogenesis of GIO, because the clinical picture of GIO mostly reflects the combined effects of the underlying systemic disease and the secondary effects induced by GC treatment.

The elucidation of the cellular and molecular mechanisms that lead to GIO and the development of improved means of identifying those at risk remain important challenges (Hong et al. 2008). It is generally accepted that reduced bone formation is the predominant effect of GCs on bone turnover (Canalis et al. 2004, Seibel et al. 2013). Results of previous studies have indicated that the induction of osteoblast apoptosis and the inhibition of osteoblast proliferation and differentiation eventually lead to a reduction in bone formation (Weinstein et al. 1998, Pereira et al. 2001, Hong et al. 2011). It has been well established from the results of both in vivo and in vitro studies that GCs regulate osteoblast apoptosis and differentiation. However, the precise molecular events that underlie the effect of GCs on proliferation pathways in osteoblasts are still not known.

MicroRNAs (miRNAs) are endogenous, non-coding RNAs that are 19-25 nucleotides in length; they regulate various biological processes, including cell proliferation, apoptosis, development, hematopoiesis, organogenesis, and tumorigenesis. miRNAs bind to matched sequences in the $3^{\prime}$-UTR of target mRNAs and either repress the translation or degrade the transcript of their target mRNAs (Zamore \& Haley 2005, Couzin 2007). miRNAs may also promote the translation of selected mRNAs in a cell-cycle-phase-dependent way (Zeng 2006). Results of recent studies have indicated that some miRNAs, such as miR-27a, miR-29a, miR-34a, miR-125b, miR-133, miR138, miR-199a, miR-206, miR-338, miR-335, and miR378 , play a crucial role in bone formation (Taipaleenmaki et al. 2012). Furthermore, results of previous studies have indicated that many of these miRNAs, including miR-27a, miR-29a, miR-34a, miR-125b, miR-199a, and miR-574, could mediate cell proliferation (Huang et al. 2012, Ma et al. 2012, Wei et al. 2012, Xu et al. 2012a,b, Chiyomaru et al. 2013, Wu et al. 2013). Moreover, these six miRNAs have been reported to regulate the WNT signaling pathway (Chiyomaru et al. 2013, Liu et al. 2013, Nagano et al. 2013, Guo et al. 2014, Rathod et al. 2014, Hashemi et al. 2015), which is a crucial regulator of GC-mediated bone acquisition and remodeling activities. Thus, we proposed the hypothesis that these molecules might be involved in GC-repressed osteoblast proliferation.

In the present study, we examined the role of miR$199 a-5 p$ in the repression of osteoblast proliferation by GCs. We detected some expression of miRNA, which has been reported to be related to bone formation and to mediate WNT signaling, in osteoblasts exposed to GCs. Several miRNAs were found to be altered, and miR-199a-5p was identified as a strong candidate for being the miRNA that was responsible for the decreased osteoblast proliferation in response to GC. Further studies confirmed that miR-199a-5p regulated osteoblast proliferation by targeting WNT signaling. Therefore, miRNAs and miRNA-regulated gene silencing may contribute to the inhibitory effects of GCs on osteoblast proliferation.

\section{Materials and methods}

\section{In vivo treatment of mice}

Seven-day-old neonatal C57 female mice were used for the present study. Stock solutions of $1 \mathrm{mg} / \mathrm{ml}$ dexamethasone (Dex) were prepared in ethanol as previously described by Gohel et al. (1999). Dosing solutions were prepared by diluting the stock solution with normal saline. After measurement of their weight, mice were given daily s.c. injections of Dex $(1.0 \mathrm{mg} / \mathrm{kg} \mathrm{BW})$. At $72 \mathrm{~h}$, mice were weighed and killed. The entire calvarium was removed for real-time quantitative reverse transcription polymerase chain reaction (real-time qRT-PCR).

\section{Cell culture}

The MC3T3-E1 cell line was supplied by the Shanghai Institute of Orthopaedics and Traumatology. Lines of less than 20 passages were used in the present study. Primary osteoblasts were obtained from neonatal murine calvaria using methods described previously (Shi et al. 2014a,b). Cells were cultured with alpha-minimal essential media ( $\alpha$-MEM) (Invitrogen) supplemented with 10\% fetal bovine serum (FBS) and $100 \mu \mathrm{g} / \mathrm{ml}$ penicillin/streptomycin. All experiments were performed under differentiation conditions, that is, in the presence of $50 \mu \mathrm{g} / \mathrm{ml}$ ascorbic acid or $4 \mathrm{mmol} / \mathrm{l} \beta$-glycerophosphate (Sigma-Aldrich). HEK293 cells were cultured in DMEM (Invitrogen). The cultures were supplemented with $10 \%$ FBS and $100 \mu \mathrm{g} / \mathrm{ml}$ penicillin/streptomycin.

Published by Bioscientifica Ltd. 


\section{Cell proliferation assay}

A cell counting kit (CCK-8) assay (Dojindo Laboratories, Kumamoto, Japan) was used to measure cell proliferation according to the manufacturer's guidelines. Briefly, cells were resuspended in $200 \mu \mathrm{l}$ cell culture medium, seeded at a density of $1 \times 10^{3}$ cells per well in 96-well microtiter plates, and incubated overnight for cell attachment. A $10 \mu \mathrm{l}$ volume of CCK-8 reagents was added to each well $1 \mathrm{~h}$ before the end of incubation. The optical density value of each sample was measured at a wavelength of $450 \mathrm{~nm}$ on a microplate reader to determine the viability of the cells. The proliferation rate was normalized to the value at time point 0 .

\section{5-ethynyl-2'-deoxyuridine assay}

Exponential-growth-phase cells were seeded into 24-well plates and incubated with serum-free $\alpha$-MEM for $24 \mathrm{~h}$. In brief, 5-ethynyl-2'-deoxyuridine (EdU) (Sigma-Aldrich) solution was added to cell culture medium to give a final concentration of 1:1000 and then incubated for $2 \mathrm{~h}$. Cell fixative (containing 4\% paraformaldehyde in PBS) was added before incubation at room temperature for $30 \mathrm{~min}$. After the cells were washed with PBS two times, click reaction buffer (100 mM Tris- $\mathrm{HCl}(\mathrm{pH} 8.5), 1 \mathrm{mM} \mathrm{CuSO}$, $100 \mu \mathrm{M}$ Apollo 550 fluorescent azide, $100 \mathrm{mM}$ ascorbic acid) was added for 10-30 min while the cells were protected from light. Then, cells were washed three times with $0.5 \%$ Triton X-100 and subsequently stained with Hoechst $(5 \mu \mathrm{g} / \mathrm{ml})$ for $30 \mathrm{~min}$ at room temperature. Samples were stored in the dark at $4{ }^{\circ} \mathrm{C}$ until they were examined using a fluorescence microscope (Olympus). EdU-positive cells were calculated by the following formula: (EdU add-in cells/Hoechst stained cells) $\times 100 \%$.

\section{5-(and-6)-carboxyfluorescein diacetate, succinimidyl ester assay}

Cell proliferation was measured using 5-(and-6)-carboxyfluorescein diacetate, succinimidyl ester (CFSE) staining and flow cytometry (Xu et al. 2006). Cells were incubated with CFSE (Invitrogen) at a concentration of $5 \mu \mathrm{mol} / 1$ in PBS for $15 \mathrm{~min}$ at $37^{\circ} \mathrm{C}$. The reaction was stopped by adding FCS. Cells were replated at a density of 48000 cells/well in six-well dishes and incubated for 3-5 days. After preparation by trypsinization and washing, fluorescence intensity was measured by flow cytometry, using excitation at $488 \mathrm{~nm}$ at the FL1 detection channel, and analyzed with CellQuest Software Becton Dickinson, Franklin Lakes, NJ, USA.

\section{MiR-199a-5p target gene prediction}

We used a computation and bioinformatics-based approach to predict the putative targets of miR-199a-5p through TargetScan, which is hosted by the Wellcome Trust Sanger Institute. FZD4 and WNT2 were predicted to be potential target genes of miR-199a-5p by the TargetScan program.

\section{Western blot analysis}

The protein samples were extracted from osteoblasts via procedures that have previously been described in detail (Yang et al. 2007). Protein samples (approximately $50 \mu \mathrm{g}$ ) were fractionated by SDS-PAGE (7.5-10\% polyacrylamide gels). Separated proteins were blot transferred onto a nitrocellulose membrane. After blocking with $0.1 \%$ Tween 20 and 5\% nonfat dry milk in Tris-buffered saline at room temperature for $1 \mathrm{~h}$, the membrane was incubated overnight at $4{ }^{\circ} \mathrm{C}$ in one of the following primary antibodies as an internal control: FZD4 (1:400; Peprotech, Rocky Hill, NJ, USA), WNT2 (1:400; Santa Cruz Biotechnology, Santa Cruz, CA, USA), $\beta$-catenin (1:200; Santa Cruz Biotechnology), Runx2 (1:200; Santa Cruz Biotechnology), Osterix (1:400; Santa Cruz Biotechnology), and $\beta$-actin (1:1000; Santa Cruz Biotechnology). The membrane was incubated with HRP-conjugated secondary antibody (1:2000) for $1 \mathrm{~h}$ and detected using the ECL Western Blot System (Amersham Biosciences).

\section{Synthesis of miRNAs and sequences of miR-199a-5p inhibitors}

MiR-199a-5p (sense: 5'-CCCAGUGUUCAGACUACCUGUUC-3', antisense: 5'-ACAGGUAGUCUGAACACUGGGUU- $3^{\prime}$ ) and its antisense oligonucleotides (AMOs: 5'-GAACAGGTAGTCTGAACACTGGG-3') were synthesized by Integrated DNA Technologies. Additionally, a scrambled RNA was used as a negative control (NC) (sense: 5'-UUCUCCGAACGUGUCACGUTT-3', antisense: 5'-ACGUGACACGUUCGGAGAATT-3'). DNA fragments of the 3'-UTRs of WNT2 and FZD4 mRNA containing the putative miR-199a-5p binding sequence were synthesized by Invitrogen. These fragments were then cloned into the multiple cloning sites downstream of the luciferase gene (HindIII and SpeI sites) in the pMIRREPORT luciferase miRNA expression reporter vector (Ambion Inc, Austin, TX, USA), as described previously (Yang et al. 2007).

Published by Bioscientifica Ltd. 
A

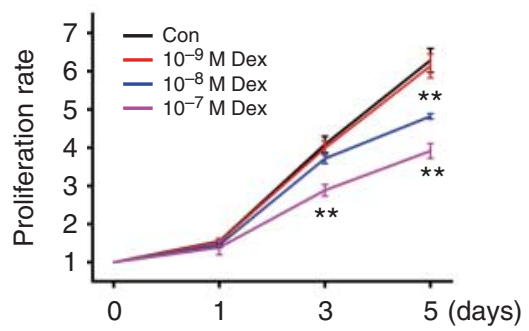

B

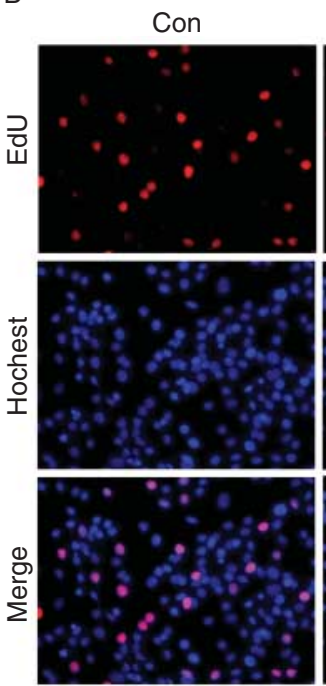

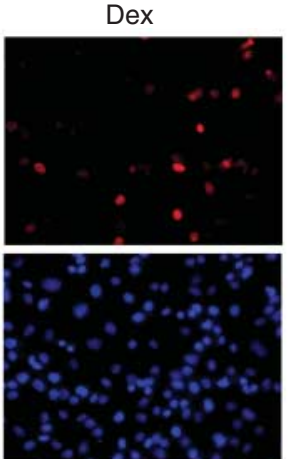

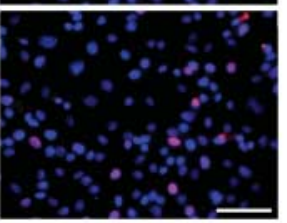

C

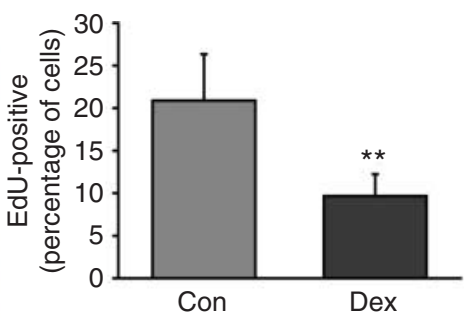

D

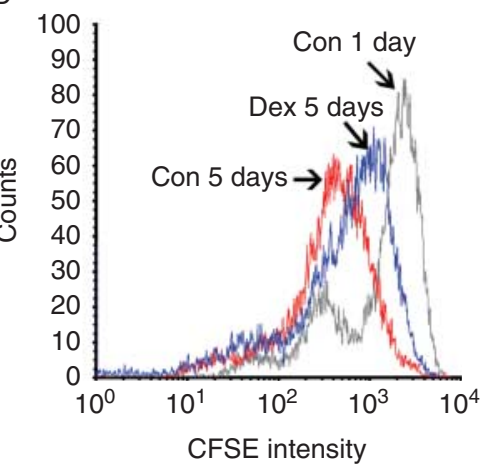

Figure 1

The inhibition of differentiating osteoblast proliferation by Dex. (A) The proliferation of MC3T3-E1 cells was measured by CCK8 after the cells were treated with $10^{-9}, 10^{-8}$, or $10^{-7} \mathrm{M}$ Dex from day 1 to day 5 . The results indicated that Dex decreased the viability of MC3T3-E1 cells in a dose- and time-dependent manner. $n=3, * * P<0.01$. (B) Representative photomicrographs $(\times 400)$ of EdU staining (top panels) and corresponding total cell photomicrographs (middle panels). Blue: Hoechst labeling of cell nuclei;

\section{Transfection of miR-199a-5p/AMO-199a-5p in osteoblasts}

The MC3T3-E1 cells/primary osteoblasts were cultured with differentiation medium for $24 \mathrm{~h}$. Osteoblasts cultured in six-well plates were divided into different groups. Osteoblasts in the control group were cultured in
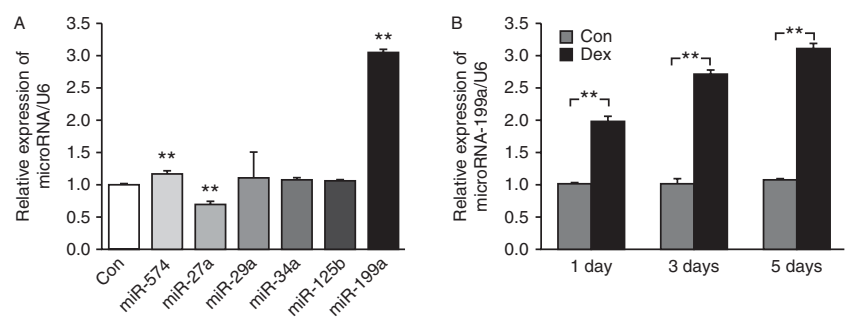

\section{Figure 2}

The upregulation of miR-199a-5p expression by Dex in differentiating osteoblasts. (A) Real-time qRT-PCR analysis of miR-574-3p, miR-27a, miR29a, miR-34a, miR-125b, and miR-199a-5p expression in MC3T3-E1 cells treated with $10^{-7} \mathrm{M}$ Dex for 5 days. $n=3, * * P<0.01$. (B) Real-time qRT-PCR analysis of miR-199a-5p expression in MC3T3-E1 cells treated with $10^{-7} \mathrm{M}$ red: EdU labeling of nuclei of proliferative cells. (C) Quantitative data showing the percentage of EdU-positive cells in different treatment groups (number of red vs number of blue nuclei). $n=3, * * P<0.01$. (D) MC3T3-E1 cells were stained with CFSE before plating, cultured for 5 days, and analyzed by flow cytometry as described in the Materials and methods section. The peak CFSE fluorescence intensity on flow cytometry was shifted by Dex. $n=3$. Con, control; Dex, dexamethasone.

differentiation culture medium. Those in the miRNA group were transfected with miR-199a-5p and/or inhibitors for $48 \mathrm{~h}$ under differentiation conditions, with X-tremeGENE siRNA Transfection Reagent (Roche), according to the manufacturer's instructions. Those in the Dex (Sigma-Aldrich) group were treated with $10^{-7} \mathrm{M}$ Dex for
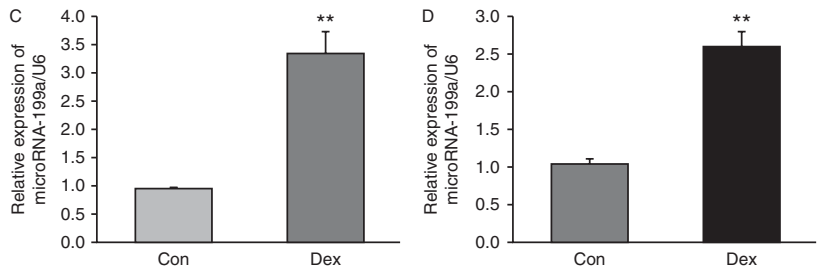

Dex from day 1 to day 5. $n=3, * * P<0.01$. (C) Real-time qRT-PCR analysis of miR-199a-5p expression in primary osteoblasts treated with $10^{-7} \mathrm{M}$ Dex for 5 days. $n=3, * * P<0.01$. (D) Real-time qRT-PCR analysis of miR-199a-5p expression in the calvarias from mice treated with Dex for 3 days. $n=3$, $* * P<0.01$. Con, control; Dex, dexamethasone; miR, microRNA.

Published by Bioscientifica Ltd. 
5 days. The miRNA and Dex group cells were transfected with miR-199a-5p and/or inhibitors for $48 \mathrm{~h}$ under $10^{-7} \mathrm{M}$ Dex and then treated with Dex for 3 days.

\section{Luciferase activity assay}

After $24 \mathrm{~h}$ of starvation in serum-free medium, HEK293 cells $\left(1 \times 10^{5}\right.$ per well $)$ were transfected with $1 \mu \mathrm{g}$ miR199a-5p/AMO-199a-5p or $1 \mu$ g PGL3 target DNA (firefly luciferase vector) and $0.1 \mu \mathrm{g}$ PRL-TK (TK-driven Renilla luciferase expression vector) with lipofectamine 2000 (Invitrogen) according to the manufacturer's instructions. Luciferase activity was measured $48 \mathrm{~h}$ after transfection with a dual luciferase reporter assay kit (Promega) on a luminometer (Lumat LB9507).

\section{Quantification of miRNA levels}

The mirVana real-time qRT-PCR miRNA Detection kit (Ambion) was used in conjunction with real-time PCR with SYBR Green I for quantification of miR-199a-5p transcript as described previously (Yang et al. 2007).

\section{Statistical analysis}

All data were analyzed using SPSS version 19.0 (SPSS, Inc.). The composite data are expressed as means \pm s.E.M. Statistical analysis was performed with one-way ANOVA followed by Dunnett's test where appropriate. Differences were considered to be significant for $P \leq 0.05$.
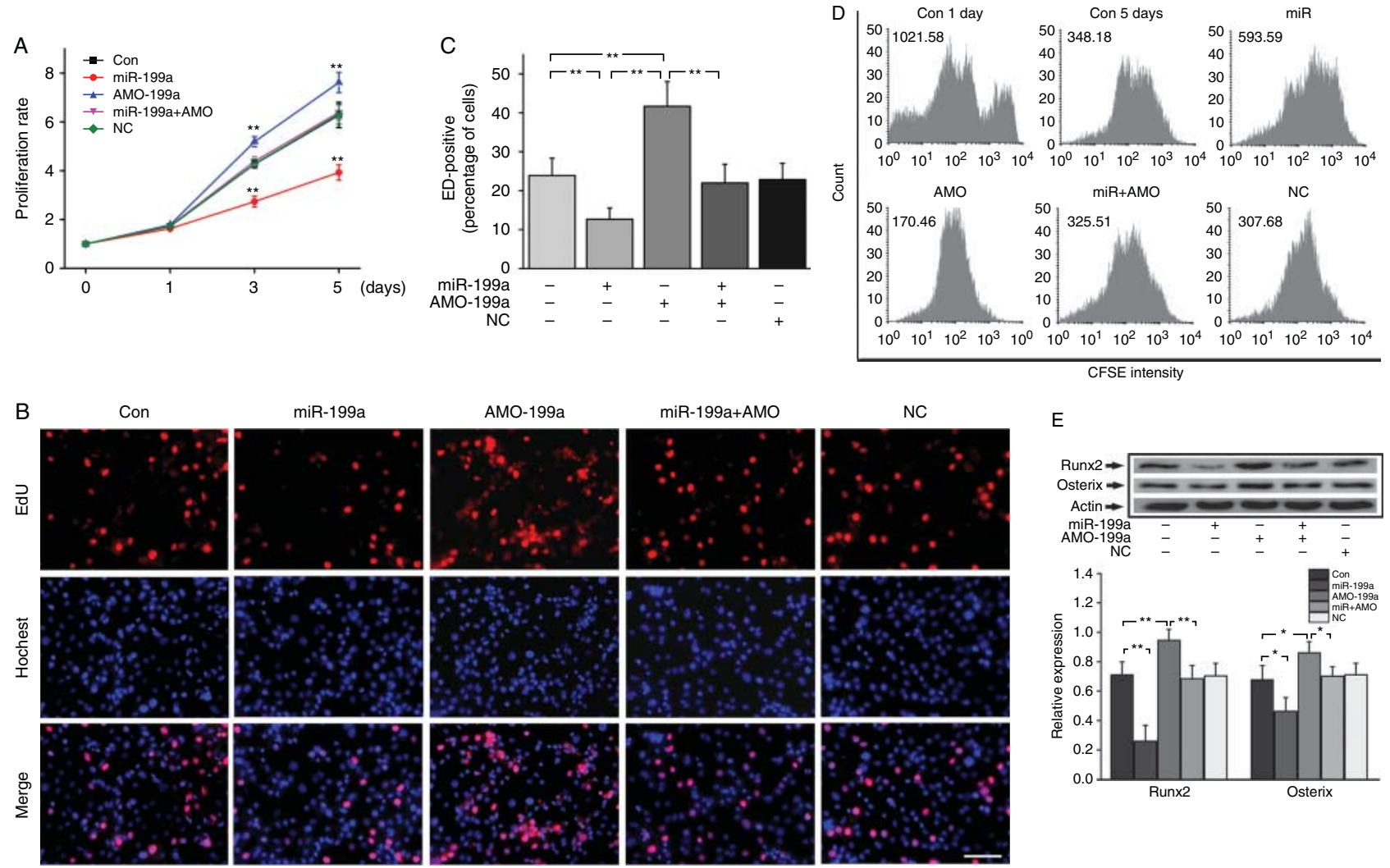

Figure 3

The repression of MC3T3-E1 cell proliferation by miR-199a-5p. (A) The proliferation of MC3T3-E1 cells was measured by CCK8 assay after cells were transfected with miR-199a-5p and/or AMO-199a-5p from day 1 to day 5. $n=3, * * P<0.01$. (B) Representative photomicrographs $(\times 400)$ of EdU staining (top panels) and corresponding total cell photomicrographs (middle panels). Blue: Hochest labeling of cell nuclei; red: EdU labeling of nuclei of proliferative cells. (C) Quantitative data showing the percentages of EdU-positive cells in different treatment groups (number of red

versus number of blue nuclei). $n=3, * * p<0.01$. (D) MC3T3-E1 cells transfected with miR-199a-5p and/or AMO-199a-5p were stained with CFSE and analyzed by flow cytometry as described in the Materials and methods section. $n=3$. (E) Western blot analysis of Runx2 and Osterix expression in MC3T3-E1 cells transfected with miR-199a-5p and/or AMO-199a-5p. $n=3, * * P<0.01, * P<0.05$. Con, control; NC, negative control; miR, microRNA.

Published by Bioscientifica Ltd. 


\section{Results}

\section{The effect of Dex on differentiating osteoblast proliferation}

To determine whether Dex regulated the proliferation of differentiating osteoblasts, we first used the CCK- 8 assay to monitor cell proliferation. MC3T3-E1 cells under differentiation conditions were treated with Dex at different concentrations $\left(0,10^{-9}, 10^{-8}\right.$, and $\left.10^{-7} \mathrm{M}\right)$ from day 1 to day 5. The results indicated that Dex decreased the proliferation of MC3T3-E1 cells in a dose- and timedependent manner (Fig. 1A).

Furthermore, MC3T3-E1 cells were stimulated with $10^{-7} \mathrm{M}$ Dex for 5 days before the EdU assay. EdU-stained photomicrographs and corresponding photomicrographs of all cells are shown in Fig. 1B. The proportion of cells with EdU-positive nuclei is shown in Fig. 1C. EdU incorporation was decreased in the Dex group, which indicates that Dex could inhibit MC3T3-E1 cell proliferation.

To further examine proliferation, MC3T3-E1cells were cultured with $10^{-7} \mathrm{M}$ Dex for 5 days and stained with CFSE. CFSE irreversibly couples to cellular proteins. When cells divide, CFSE labeling is distributed equally between daughter cells, which are half as fluorescent as their parents are. The peak CFSE fluorescence intensity on flow cytometry was shifted by Dex, which indicates that cells treated with Dex had fewer cycles of cell replication as compared with the control group (Fig. 1D).

\section{Upregulation of miR-199a-5p expression by Dex in differentiating osteoblasts}

To examine the role of miRNAs in the repression of osteoblast proliferation by Dex, we first detected some miRNA expression, which has been reported to be related to bone formation and to mediate WNT signaling, in MC3T3-E1 cells exposed to $10^{-7} \mathrm{M}$ Dex for 5 days. Several miRNAs were found to be altered, and miR-199a-5p was identified as a strong candidate for being the miRNA that was responsible for the GC-decreased osteoblast proliferation. We found that miR-574$3 p$ and miR-27a were weakly affected during this time frame. However, the expression of miR-199a-5p was significantly upregulated by Dex (Fig. 2A). The results of studies indicated that Dex increased the expression of miR-199a-5p in a time-dependent manner (Fig. 2B). Similarly, the upregulation of miR-199a-5p expression was also observed in primary osteoblasts treated with
A
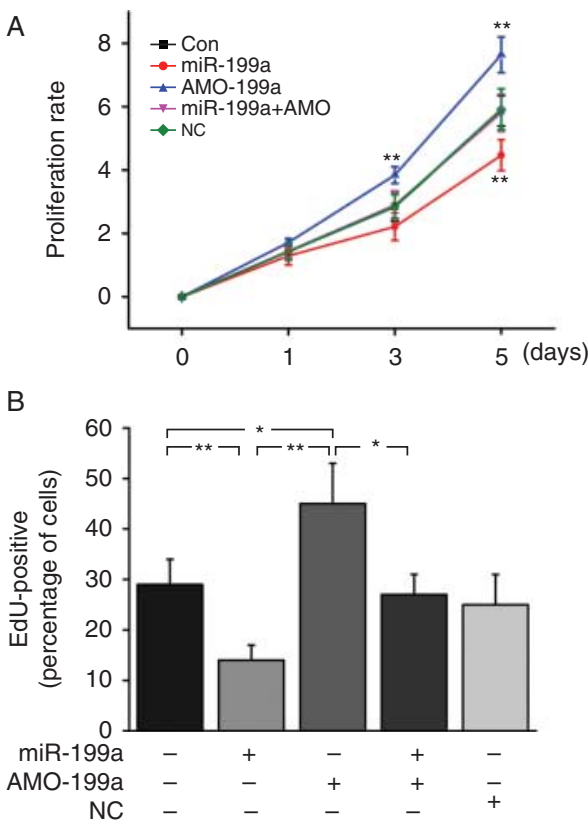
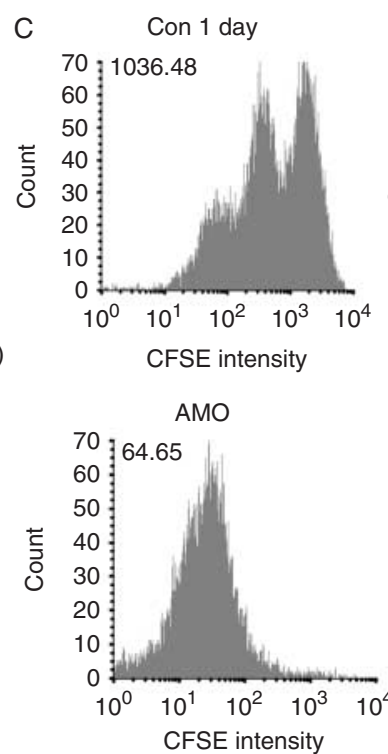
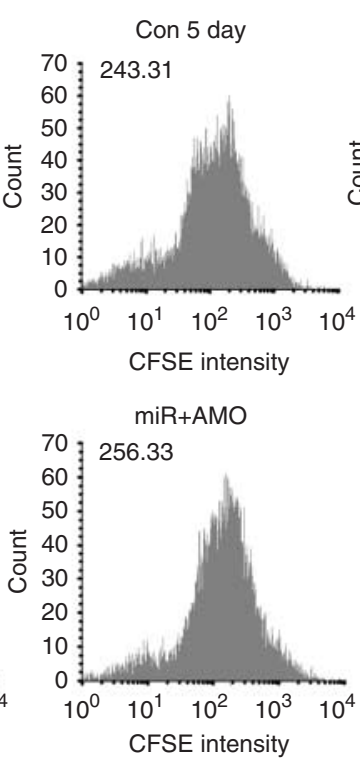
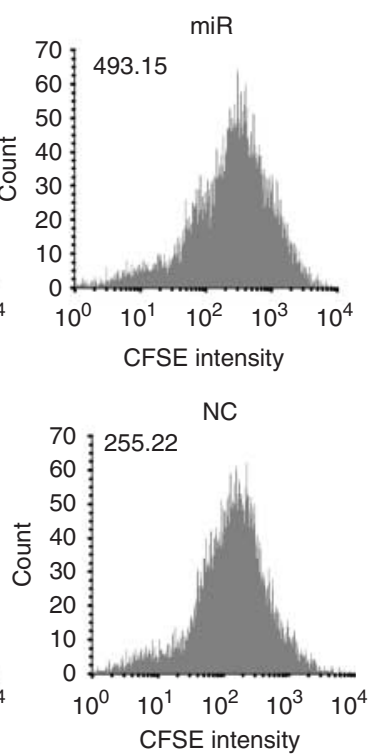

Figure 4

The repression of primary osteoblast proliferation by miR-199a-5p. (A) Proliferation of primary osteoblasts was measured by CCK8 assay after cells were transfected with miR-199a-5p and/or AMO-199a-5p from day 1 to day 5. $n=3, * * P<0.01$. (B) Quantitative data showing the percentages of EdU-positive cells in different treatment groups (number of red versus
(C) 2015 Society for Endocrinology Printed in Great Britain number of blue nuclei). $n=3, * * P<0.01, * P<0.05$. (C) Primary osteoblasts transfected with miR-199a-5p and/or AMO-199a-5p were stained with CFSE and analyzed by flow cytometry as described in the Materials and methods section. $n=3$. Con, control; NC, negative control; miR, microRNA.

Published by Bioscientifica Ltd. 
$10^{-7} \mathrm{M}$ Dex for 5 days (Fig. 2C). Furthermore, we observed the effects of Dex on miR-199a-5p expression in vivo. We found that the expression of miR-199a-5p was significantly upregulated in calvarias from mice treated with Dex (Fig. 2D). Thus, we proposed the hypothesis that miR-199a-5p might be involved in Dex-decreased osteoblast proliferation.

\section{Repression of differentiating osteoblast proliferation by miR-199a-5p}

To delineate the role of miR-199a-5p in osteoblast proliferation, we performed loss-of-function and gainof-function experiments in which we decreased and increased the quantities of miR-199a-5p with a miR199a-5p inhibitor and a miR-199a-5p mimic respectively. MC3T3-E1 cells were transfected with miR-199a-5p and/or AMO-199a-5p from day 1 to day 5. Then we assessed cell proliferation with CCK-8 assays. We found that overexpression of miR-199a-5p decreased MC3T3-E1 cell proliferation. However, the depletion of miR-199a-5p with AMO-199a-5p resulted in increased MC3T3-E1 cell proliferation.
Furthermore, the results of EdU assays by fluorescence microscopy further indicated that miR-199a-5p mimic clearly decreased MC3T3-E1 cell proliferation (Fig. 3B and C), and miR-199a-5p inhibitor significantly increased osteoblast proliferation. Similar results were further confirmed by the results of CFSE fluorescence intensity assays (Fig. 3D). In addition, the effect of miR-199a-5p on osteoblast differentiation was examined using western blotting. The levels of expression of osteogenic marker genes, including Runx2 and Osterix, were significantly affected in MC3T3-E1 cells that had been transfected with miR-199a-5p and/or AMO-199a-5p for $48 \mathrm{~h}$, which indicates that miR-199a-5p is also involved in osteoblast differentiation (Fig. 3E).

Furthermore, primary osteoblasts were also used to test the effects of miR-199a-5p on cell proliferation. The proliferation of primary osteoblasts transfected with miR199a-5p and/or AMO-199a-5p was measured by CCK8, EdU assay, and CFSE fluorescence intensity assay. Similarly, we found that miR-199a-5p significantly decreased primary osteoblast proliferation, and AMO-199a-5p increased it (Fig. 4A, B and C). Taken together, these results indicate that miR-199a-5p could regulate osteoblast proliferation.

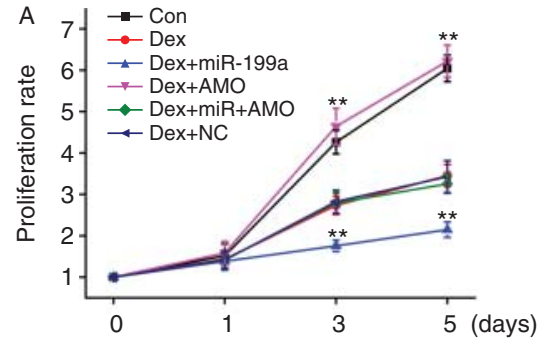

B

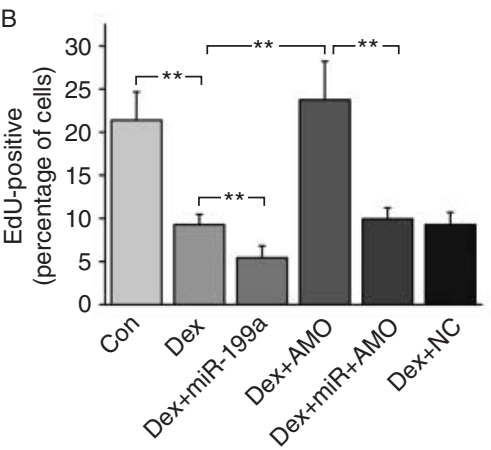

C

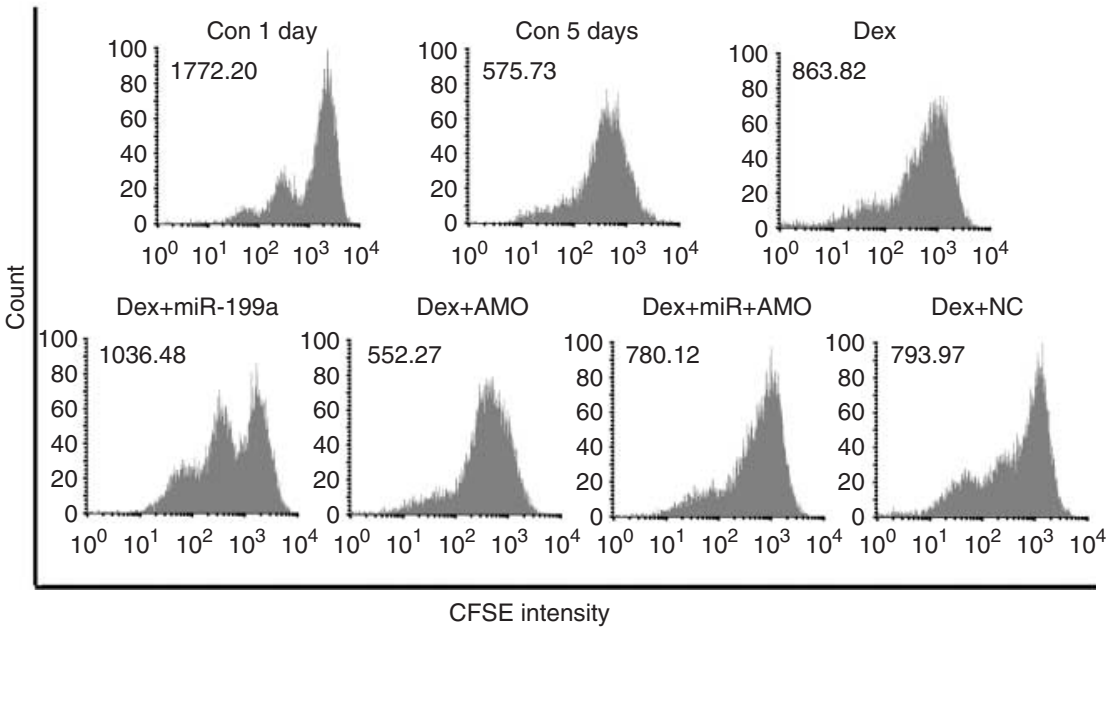

\section{Figure 5}

The involvement of miR-199a-5p in Dex-reduced MC3T3-E1 cell proliferation. (A) The proliferation of MC3T3-E1 cells was measured by CCK 8 assay after cells were transfected with miR-199a-5p and/or AMO-199a-5p under Dex from day 1 to day 5. $n=3, * * P<0.01$. (B) Quantitative data showing the percentage of EdU-positive cells in different treatment groups (number of
(C) 2015 Society for Endocrinology Printed in Great Britain red versus number of blue nuclei). $n=3, * * P<0.01$. (C) MC3T3-E1 cells transfected with miR-199a-5p and/or AMO-199a-5p under Dex were stained with CFSE and analyzed by flow cytometry as described in the Materials and methods section. $n=3$. Con, control; Dex, dexamethasone; $\mathrm{NC}$, negative control; miR, microRNA. 

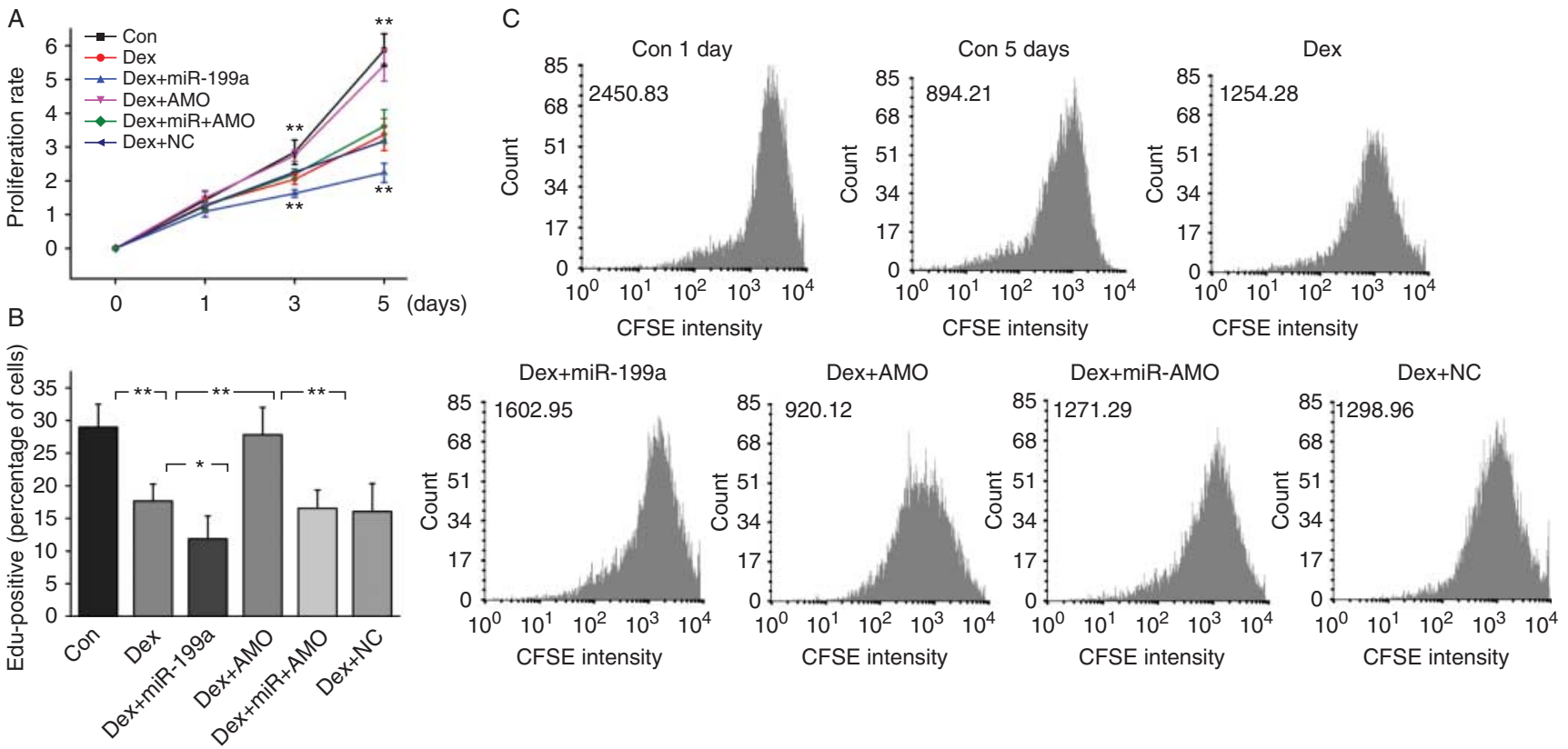

\section{Figure 6}

The involvement of miR-199a-5p in Dex-reduced primary osteoblast proliferation. (A) The proliferation of primary osteoblasts was measured by CCK8 assay after cells were transfected with miR-199a-5p and/or AMO199a-5p under Dex from day 1 to day 5. $n=3, * * P<0.01$. (B) Quantitative data showing the percentage of EdU-positive cells in different treatment

\section{Involvement of miR-199a-5p in the reduction of osteoblast proliferation in response to Dex}

We consequently investigated whether miR-199a-5p was involved in the decreased osteoblast proliferation in response to Dex. To this end, we observed the effect of Dex on proliferation in MC3T3-E1 cells transfected with miR199a-5p and/or AMO-199a-5p for 5 days. The results of CCK-8 assays indicated that miR-199a-5p markedly increased the reduction in MC3T3-E1 cell proliferation in response to Dex. Furthermore, the co-application of miR199a-5p and AMO-199a-5p almost completely abolished the effect of miR-199a-5p. Moreover, the inhibitory effect of Dex on MC3T3-E1 cell proliferation was significantly alleviated when MC3T3-E1 cells alone were transfected with AMO-199a-5p, which indicates that miR-199a-5p is involved in Dex-decreased osteoblast proliferation (Fig. 5A). Similar results were further confirmed by the results of EdU assay and flow cytometric analysis of CFSE intensity (Fig. 5B and C). All of these results were further verified in primary osteoblasts (Fig. 6A, B and C). groups (number of red versus number of blue nuclei). $n=3, * * P<0.01$, $* P<0.05$. (C) Primary osteoblasts transfected with miR-199a-5p and/or AMO-199a-5p under Dex were stained with CFSE and analyzed by flow cytometry as described in the Materials and methods section. $n=3$. Con, control; Dex, dexamethasone; NC, negative control; miR, microRNA.

\section{Repression of WNT signaling by miR-199a-5p transfection}

The observations presented in the previous sections indicate that miR-199a-5p is involved in osteoblast proliferation. It is possible that miR-199a-5p targets several regulatory factors related to osteoblast proliferation. To address this issue, we used a computational and bioinformatics-based approach to predict the putative targets related to proliferation through TargetScan. These explorations led to the identification of candidate targets of miR-199a-5p: WNT signaling, including FZD4 and WNT2 (Fig. 7A and B). Results of western blot analysis of FZD4 and WNT2 expression in the MC3T3-E1 cells treated with $10^{-7} \mathrm{M}$ Dex for 5 days are shown in Fig. 7C and D. We found that Dex decreased FZD4 and WNT2 expression in MC3T3-E1 cells. To verify that FZD4 and WNT2 are indeed repressed post-transcriptionally by miR-199a-5p, we determined the effect of miR-199a-5p on protein expression. The results of western blot analysis indicated that miR-199a-5p markedly lowered the levels of FZD4 and WNT2 proteins in MC3T3-E1 (Fig. 7E and F). Co-application of miR-199a-5p and AMO-199a-5p almost completely

Published by Bioscientifica Ltd. 
A

Predicted pairing of FZD4 $3^{\prime} U T R$ and miR-199a-5p mmu-miR-199a-5p 3'-CUUGUCCAUCAGACUUGUGACCC-5' FZD4 3'UTR 5\%CAAAGUGAUCUAUAAACACUGGA.-3 5'-CAAAGUGAUCUAUAAACACUGGA-3' Hsa -CU-AUAAACACUGGAGAC Rho -CU-AUAAACACUGGAGAC Mmu-CU-AUAAACACUGGAGAC Mm1--CU-AUAAAACACUGGAGAC Oga -CU-AUAAACACUGGAGAC

C
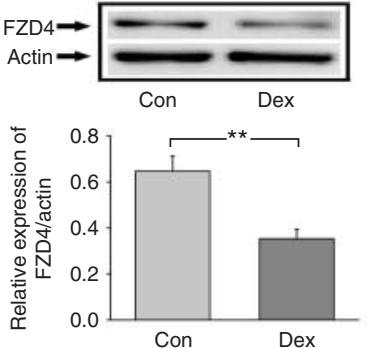

$E$
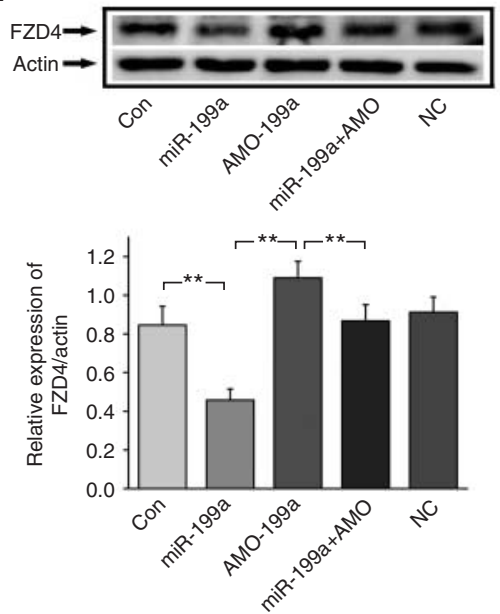

\section{Figure 7}

The repression of WNT signaling by miR-199a-5p transfection. (A) The sequences showing the unique sites of miRNA::mRNA complementarity between miR-199a-5p and FZD4. (B) The sequences showing the unique sites of miRNA::mRNA complementarity between miR-199a-5p and WNT2. (C) Western blot analysis of FZD4 expression in MC3T3-E1 cells treated with $10^{-7} \mathrm{M}$ Dex for 5 days. $n=3, * * P<0.01$. (D) Western blot analysis of WNT2 expression in MCЗТ3-E1 cells treated with $10^{-7} \mathrm{M}$ Dex for 5 days. $n=3$,

abolished the effect of miR-199a-5p. Moreover, application of AMO-199a-5p alone increased the levels of FZD4 and WNT2 in MC3T3-E1, which indicates that there is a basal level of miR-199a-5p activity in osteoblasts (Fig. 7E and F). Similarly, we also tested the effects of miR-199a-5p on the levels of FZD4 and WNT2 proteins in primary osteoblasts. The results indicated that miR-199a-5p significantly decreased FZD4 and WNT2 protein expression, and AMO-199a-5p increased it (Fig. 8A and B). In addition, we observed the effect of miR-199a-5p on the expression of $\beta$-catenin, a key mediator of the WNT signaling pathway, in primary osteoblasts. We found that miR-199a-5p
B

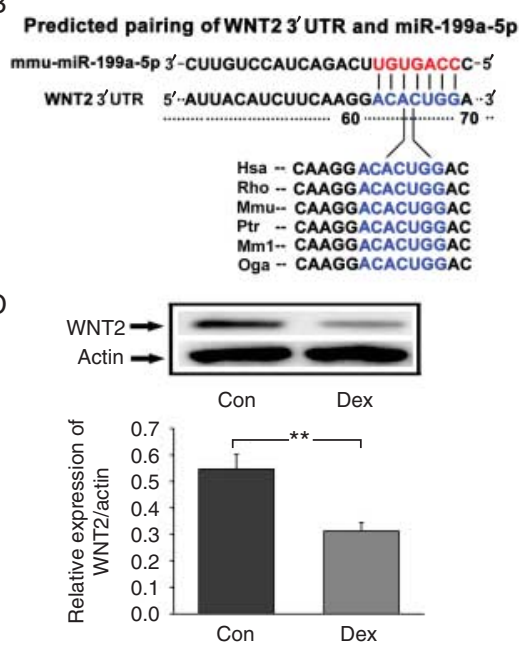

$\mathrm{F}$

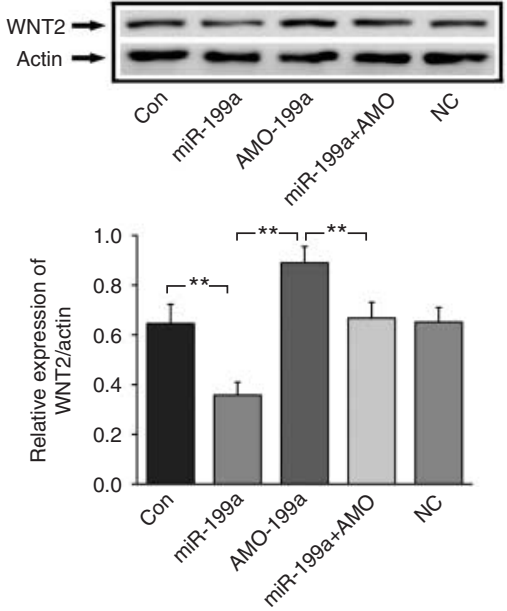

$* * P<0.01$. (E) Western blot analysis of FZD4 expression in MC3T3-E1 cells transfected with miR-199a-5p and/or AMO-199a-5p for 48 h. $n=3$, $* * P<0.01$. (F) Western blot analysis of WNT2 expression in MC3T3-E1 cells transfected with miR-199a-5p and/or AMO-199a-5p for 48 h. $n=3$, $* * P<0.01$. Con, control; Dex, dexamethasone; NC, negative control; miR, microRNA.

decreased $\beta$-catenin expression, which indicates that miR-199a-5p could inhibit WNT signaling (Fig. 8B).

\section{Verification of interactions between miR-199a-5p and its target genes}

We constructed chimeric vectors by placing the 3 '-UTRs of FZD4 and WNT2 into the $3^{\prime}$-UTR of a luciferase reporter plasmid. We performed luciferase reporter assays using HEK293 cells that do not express miR-199a-5p (data not shown). Compared with the NC, transfection of miR-199a-5p with the luciferase reporter gene linked to

Published by Bioscientifica Ltd 
A
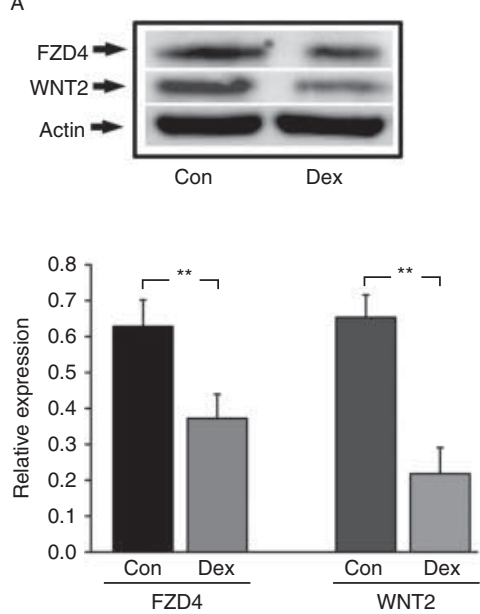

B
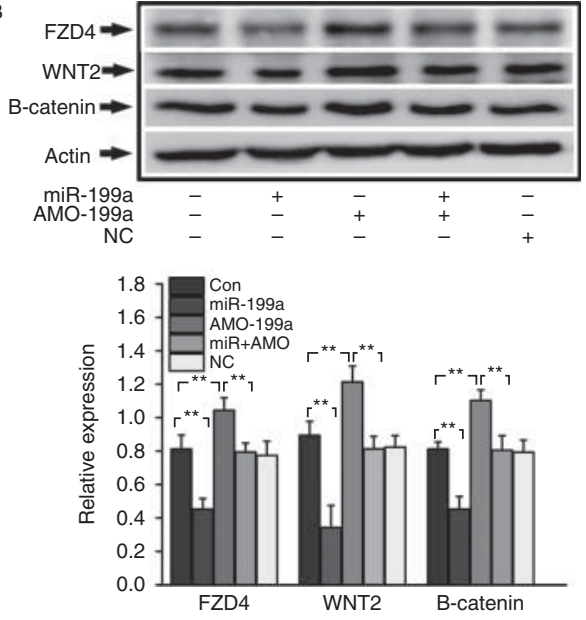

\section{Figure 8}

The repression of WNT signaling by transfection with miR-199a-5p. (A) Western blot analysis of FZD4 and WNT2 expression in primary osteoblasts treated with $10^{-7} \mathrm{M}$ Dex for 5 days. $n=3, * * P<0.01$.

(B) Western blot analysis of FZD4, WNT2, and $\beta$-catenin expression in

the 3 -UTR of FZD4 or WNT2 resulted in a significant decrease in luciferase activity, and co-application of miR-199a-5p with AMO-199a-5p alleviated the decrease in luciferase activity, whereas AMO-199a-5p alone had no effect (Fig. 9A and B). These results indicate that FZD4 and WNT2 are the targets of miR-199a-5p.

Successful delivery of miR-199a-5p, AMO-199a-5p, and NC to the cells was further verified by comparing the miR-199a-5p levels $48 \mathrm{~h}$ after transfection of the constructs in MC3T3-E1 cells and primary osteoblasts. Transfection resulted in a significant increase in miR-199a-5p levels (Fig. 9C). It is worth noting that miR199a-5P levels were dynamic after transfection. The data were collected $48 \mathrm{~h}$ after transfection because the plateau level was reached at that time. These results proved the feasibility of all of the experiments.

\section{Discussion}

Increased concentrations of GCs could cause the development of Cushing's syndrome with severe osteoporosis. Results of previous studies have indicated that GCs have potent inhibitory effects on osteoblast proliferation (Walsh et al. 2001, Hong et al. 2011). However, the molecular mechanisms involved in GC-inhibited osteoblast proliferation are still poorly understood. In the present study, we showed that miR-199a-5p plays a significant role in GC-decreased osteoblast proliferation by regulating the WNT signaling pathway. primary osteoblasts transfected with miR-199a-5p and/or AMO-199a-5p for 48 h. $n=3, * * P<0.01$. Con, control; Dex, dexamethasone; NC, negative control; miR, microRNA.

Results described in several recent reports have indicated that GCs exert post-transcriptional control through the regulation of miRNA processing and expression (De Iudicibus et al. 2013). Xing et al. (2014) reported that GCs induced apoptosis by inhibiting miRNA cluster miR-17-92 expression in chondrocytic cells. Furthermore, miR-29b and miR-29c have been reported to be involved in the Toll-like receptor control of GC-induced apoptosis in human plasmacytoid dendritic cells (Hong et al. 2013). In addition, miRNAs could also negatively regulate the GC receptor (GR) transcriptional response by directly targeting the $3^{\prime}$-UTR of GR $\alpha$ mRNA (Lv et al. 2012). It is also known that osteoblasts are critical target cells of GCs. Results of our previous studies indicated that miR-17-92a downregulation by GCs leads to Bim targeting and to the induction of osteoblast apoptosis (Guo et al. 2013). Furthermore, GCs could also increase receptor activator of nuclear factor $B$ ligand expression by downregulating miR-17/20a in osteoblasts, which indirectly enhances osteoclastogenesis and bone resorption (Shi et al. 2014a,b). However, to our knowledge, there have been no reports on whether miRNA expression could be regulated by GCs in osteoblast proliferation. The present study is the first to observe the effect of GCs on miRNAs in osteoblast proliferation.

We detected some miRNA expression in osteoblasts that were exposed to GCs. These miRNAs have been reported to be related to cell proliferation and bone formation in previous studies (Huang et al. 2012,

Published by Bioscientifica Ltd 
A

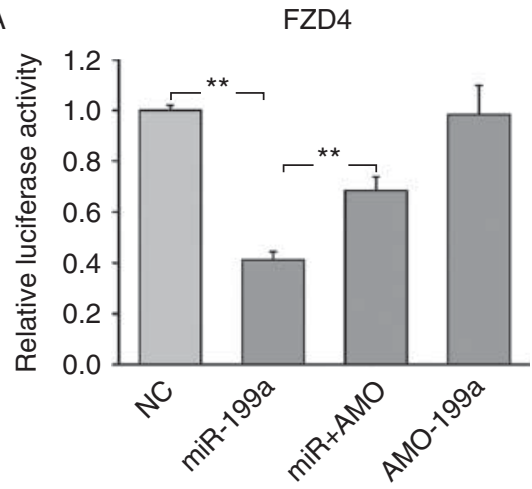

B
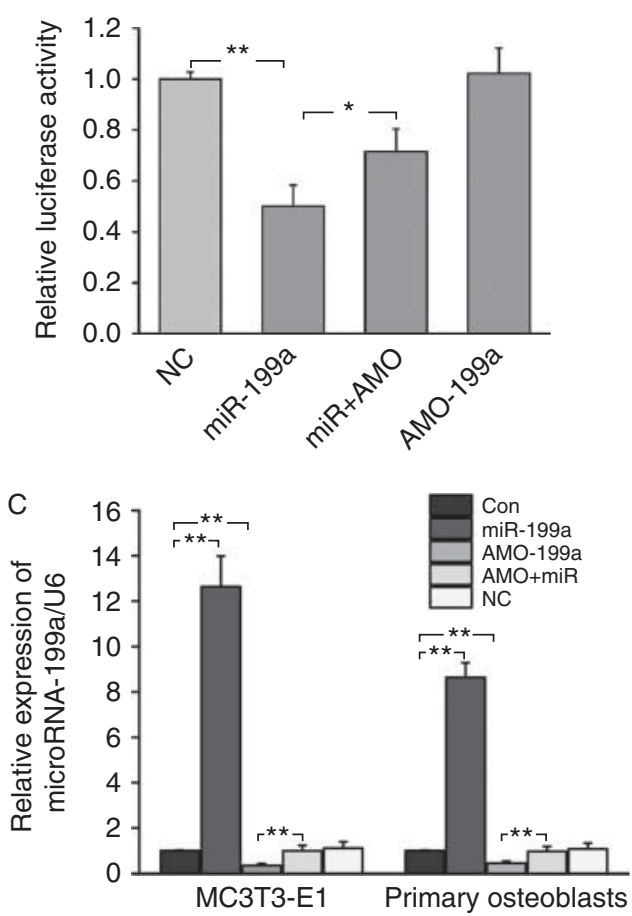

Figure 9

Verification of the interactions between miR-199a-5p and their target genes. (A) Verification of FZD4 as a cognate target of miR-199a-5p. Data on luciferase reporter activity show the interaction between miR-199a-5p and FZD4 $3^{\prime}$-UTRs. $n=3, * * P<0.01$. (B) Verification of WNT2 as a cognate target of miR-199a-5p. Data on luciferase reporter activity shows the interaction between miR-199a-5p and WNT2 3 '-UTRs. $n=3, * * P<0.01, * P<0.05$. (C) MiR-199a-5p levels in MC3T3-E1 cells and primary osteoblasts with transfection of sequence determined by real-time qRT-PCR. $n=3$, $* * P<0.01$. Con, control; NC, negative control; miR, microRNA.

Ma et al. 2012, Taipaleenmaki et al. 2012, Wei et al. 2012, Xu et al. 2012a,b, Chiyomaru et al. 2013, Wu et al. 2013). Furthermore, these miRNAs could mediate WNT signaling (Chiyomaru et al. 2013, Liu et al. 2013, Nagano et al. 2013, Guo et al. 2014, Rathod et al. 2014, Hashemi et al. 2015), a crucial factor in decreased bone formation in response to GCs. Therefore, we first examined whether these six
miRNAs were involved in the regulation of osteoblast proliferation by GCs. The results indicated that only miR199a-5p was a strong candidate for being responsible for the decreased osteoblast proliferation in response to GCs. We speculated that miRNAs might play different roles in different cells. The present study did not apply miRNA chips to screen miRNA expression in response to the decreased osteoblast proliferation due to GCs. Therefore, several differentially expressed miRNAs may have been missed. Future studies are required to identify other miRNAs involved in the inhibition of osteoblast proliferation in response to GCs.

The present results indicated that miR-199a-5p was significantly increased during the decreased osteoblast proliferation in response to Dex. Furthermore, overexpression of miR-199a-5p decreased osteoblast proliferation. However, the depletion of miR-199a-5p with AMO-199a-5p resulted in an increased proliferation of osteoblasts. Results of previous studies have indicated that miR-199a-5p is a ubiquitously expressed miRNA whose expression is modulated at key time points during development, growth, and regeneration in cancers (Xu et al. 2012a,b, Alexander et al. 2013, Shi et al. 2014a,b). Shi et al. $(2014 a, b)$ showed that miR-199a-5p affects porcine preadipocyte proliferation and differentiation. Alexander et al. (2013) found that miR-199a-5p affects WNT signaling, cell proliferation, and myogenic differentiation. Furthermore, lentivirus-mediated overexpression of miR199a-5p has been shown to inhibit cell proliferation in human hepatocellular carcinoma (Xu et al. 2012a,b). Although the role of miR-199a-5p in the pathogenesis of several diseases, including breast cancer, lymphoma, and pulmonary hypertension, was reported as part of these studies, the present study is the first, to our knowledge, to uncover the role of miR-199a-5p in metabolic bone diseases and osteoblast proliferation.

GCs, which regulate diverse physiological effects, have both genomic and nongenomic mechanisms (Stahn \& Buttgereit 2008). The steroid's nongenomic effects occur within seconds to minutes and are mediated by the GR or by another means, such as G-protein-coupled receptors (Stahn \& Buttgereit 2008). It has been demonstrated that GCs are unable to suppress bone formation in the absence of GR expression in osteoblasts because their proliferation, differentiation, and apoptosis become immune to GCs (Rauch et al. 2010). Therefore, the GC-inhibited proliferation of osteoblasts is triggered via GR-dependent transcriptional regulation. Results from a previous study indicated that GCs could regulate miRNA expression via a GR-mediated direct DNA binding mechanism

Published by Bioscientifica Ltd. 
(De Iudicibus et al. 2013). In the present study, we did not explore whether GR was involved in the regulation of miR199a-5p by GCs in osteoblasts. Therefore, further studies need to be performed to uncover the role of GC-regulated miR-199a-5p in osteoblasts. WNT/ $\beta$-catenin signaling plays an important role in bone development and metabolism by controlling both bone formation and resorption (Wang et al. 2014). Wnt ligands are secreted molecules that bind to cell-surface receptors that are encoded by the Frizzled and LDL-receptor-related proteins. Once bound, the ligands initiate a cascade of intracellular events that activate $\beta$-catenin activity and the DNA binding protein TCF, which eventually results in the transcription of target genes (Wang et al. 2014). It has been confirmed that GCs could inhibit canonical WNT signaling to suppress bone formation (Guanabens et al. 2014). In the present study, miR-199a-5p was involved in GC-inhibited osteoblast proliferation insofar as it targeted WNT signaling. The results of previous studies have also indicated that miR-199a-5p could target several factors that regulate cell proliferation within the WNT signaling pathway, including FZD4 and WNT2 (Alexander et al. 2013).

Our data provide new evidence that miR-199a-5p plays a dominant role in GC-inhibited osteoblast proliferation. The inhibitory effect of miR-199a-5p on osteoblast proliferation involves the disruption of WNT signaling. The present study is an effort to better understand the molecular mechanism of GIO and to provide new insights into the potential contribution of miRNAs to GCmediated osteoblast proliferation and bone formation.

\section{Declaration of interest}

The authors declare that there is no conflict of interest that could be perceived as prejudicing the impartiality of the research reported.

\section{Funding}

This work was supported by the National Natural Science Foundation of China (grant number 81300713); the Innovation Program of Shanghai Municipal Education Commission (grant number 14YZ044); and the Shanghai Jiaotong University School of Medicine (grant number 13XJ10060)

\section{Author contribution statement}

L G and C G S were involved in the conception and hypothesis delineation; $L G$ and $C G S$ designed the experiments, conducted the luciferase and quantitative real-time PCR experiments, and wrote the manuscript; J Q, B H, $H B Z$, and $H K$ performed the EdU staining and CFSE assay; $\mathrm{PH}$ modified the manuscript; $\mathrm{M} \mathrm{J}$ and $\mathrm{P} \mathrm{H}$ performed part of the luciferase and western blot analyses; and L F D designed and conducted the animal studies.

\section{Acknowledgements}

The authors thank Dr Zhaoping Qiu for expert technical assistance in carrying out the real-time RT-PCR and western blotting analyses.

\section{References}

Alexander MS, Kawahara G, Motohashi N, Casar JC, Eisenberg I, Myers JA Gasperini MJ, Estrella EA, Kho AT, Mitsuhashi S et al. 2013 MicroRNA199a is induced in dystrophic muscle and affects WNT signaling, cell proliferation, and myogenic differentiation. Cell Death and Differentiation 20 1194-1208. (doi:10.1038/cdd.2013.62)

Canalis E, Bilezikian JP, Angeli A \& Giustina A 2004 Perspectives on glucocorticoid-induced osteoporosis. Bone 34 593-598. (doi:10.1016/ j.bone.2003.11.026)

Chiyomaru T, Yamamura S, Fukuhara S, Hidaka H, Majid S, Saini S, Arora S, Deng G, Shahryari V, Chang I et al. 2013 Genistein up-regulates tumor suppressor microRNA-574-3p in prostate cancer. PLOS ONE 8 e58929. (doi:10.1371/journal.pone.0058929)

Couzin J 2007 Genetics. Erasing microRNAs reveals their powerful punch. Science 316 530. (doi:10.1126/science.316.5824.530)

De Iudicibus S, Lucafo M, Martelossi S, Pierobon C, Ventura A \& Decorti G 2013 MicroRNAs as tools to predict glucocorticoid response in inflammatory bowel diseases. World Journal of Gastroenterology 19 7947-7954. (doi:10.3748/wjg.v19.i44.7947)

Gohel A, McCarthy MB \& Gronowicz G 1999 Estrogen prevents glucocorticoid-induced apoptosis in osteoblasts in vivo and in vitro. Endocrinology 140 5339-5347. (doi:10.1210/endo.140.11.7135)

Guanabens N, Gifre L \& Peris P 2014 The role of Wnt signaling and sclerostin in the pathogenesis of glucocorticoid-induced osteoporosis. Current Osteoporosis Reports 12 90-97. (doi:10.1007/s11914-014-0197-0)

Guo L, Xu J, Qi J, Zhang L, Wang J, Liang J, Qian N, Zhou H, Wei L \& Deng L 2013 MicroRNA-17-92a upregulation by estrogen leads to Bim targeting and inhibition of osteoblast apoptosis. Journal of Cell Science $\mathbf{1 2 6}$ 978-988. (doi:10.1242/jcs.117515)

Guo D, Li Q, Lv Q, Wei Q, Cao S \& Gu J 2014 MiR-27a targets sFRP1 in hFOB cells to regulate proliferation, apoptosis and differentiation. PLOS ONE 9 e91354. (doi:10.1371/journal.pone.0091354)

Hashemi GA, Burkhard FC, Rehrauer H, Aquino FC \& Monastyrskaya K 2015 MicroRNA MiR-199a-5p regulates smooth muscle cell proliferation and morphology by targeting WNT2 signaling pathway. Journal of Biological Chemistry 290 7067-7086. (doi:10.1074/jbc.M114.618694)

Hong D, Chen HX, Ge RS \& Li JC 2008 The biological roles of extracellular and intracytoplasmic glucocorticoids in skeletal cells. Journal of Steroid Biochemistry and Molecular Biology 111 164-170. (doi:10.1016/j.jsbmb. 2008.06.015)

Hong D, Chen HX, Yu HQ, Wang C, Deng HT, Lian QQ \& Ge RS 2011 Quantitative proteomic analysis of dexamethasone-induced effects on osteoblast differentiation, proliferation, and apoptosis in MC3T3-E1 cells using SILAC. Osteoporosis International 22 2175-2186. (doi:10.1007/s00198-010-1434-8)

Hong Y, Wu J, Zhao J, Wang H, Liu Y, Chen T, Kan X, Tao Q, Shen X, Yan K et al. 2013 miR-29b and miR-29c are involved in Toll-like receptor control of glucocorticoid-induced apoptosis in human plasmacytoid dendritic cells. PLoS ONE 8 e69926. (doi:10.1371/journal.pone. 0069926)

Huang Z, Chen X, Yu B, He J \& Chen D 2012 MicroRNA-27a promotes myoblast proliferation by targeting myostatin. Biochemical and Biophysical Research Communications 423 265-269. (doi:10.1016/j.bbrc. 2012.05.106)

Kondo T, Kitazawa R, Yamaguchi A \& Kitazawa S 2008 Dexamethasone promotes osteoclastogenesis by inhibiting osteoprotegerin through multiple levels. Journal of Cellular Biochemistry 103 335-345. (doi:10.1002/jcb.21414) 
Liu Z, Liu H, Desai S, Schmitt DC, Zhou M, Khong HT, Klos KS, McClellan S, Fodstad O \& Tan M 2013 miR-125b functions as a key mediator for snail-induced stem cell propagation and chemoresistance. Journal of Biological Chemistry 288 4334-4345. (doi:10.1074/jbc.M112.419168)

Lv M, Zhang X, Jia H, Li D, Zhang B, Zhang H, Hong M, Jiang T, Jiang Q, Lu J et al. 2012 An oncogenic role of miR-142-3p in human T-cell acute lymphoblastic leukemia (T-ALL) by targeting glucocorticoid receptor- $\alpha$ and cAMP/PKA pathways. Leukemia 26 769-777. (doi:10.1038/ leu.2011.273)

Ma W, Xie S, Ni M, Huang X, Hu S, Liu Q, Liu A, Zhang J \& Zhang Y 2012 MicroRNA-29a inhibited epididymal epithelial cell proliferation by targeting nuclear autoantigenic sperm protein (NASP). Journal of Biological Chemistry 287 10189-10199. (doi:10.1074/jbc.M111.303636)

Nagano H, Tomimaru Y, Eguchi H, Hama N, Wada H, Kawamoto K, Kobayashi S, Mori M \& Doki Y 2013 MicroRNA-29a induces resistance to gemcitabine through the Wnt/ $\beta$-catenin signaling pathway in pancreatic cancer cells. International Journal of Oncology 43 1066-1072. (doi:10.3892/ijo.2013.2037)

Pereira RM, Delany AM \& Canalis E 2001 Cortisol inhibits the differentiation and apoptosis of osteoblasts in culture. Bone $\mathbf{2 8}$ 484-490. (doi:10.1016/S8756-3282(01)00422-7)

Rathod SS, Rani SB, Khan M, Muzumdar D \& Shiras A 2014 Tumor suppressive miRNA-34a suppresses cell proliferation and tumor growth of glioma stem cells by targeting Akt and Wnt signaling pathways. FEBS Open Bio 4 485-495. (doi:10.1016/j.fob.2014.05.002)

Rauch A, Seitz S, Baschant U, Schilling AF, Illing A, Stride B, Kirilov M, Mandic V, Takacz A, Schmidt-Ullrich R et al. 2010 Glucocorticoids suppress bone formation by attenuating osteoblast differentiation via the monomeric glucocorticoid receptor. Cell Metabolism 11 517-531. (doi:10.1016/j.cmet.2010.05.005)

Seibel MJ, Cooper MS \& Zhou H 2013 Glucocorticoid-induced osteoporosis: mechanisms, management, and future perspectives. Lancet. Diabetes \& Endocrinology 1 59-70. (doi:10.1016/S2213-8587(13)70045-7)

Shi C, Qi J, Huang P, Jiang M, Zhou Q, Zhou H, Kang H, Qian N, Yang Q, Guo L et al. 2014a MicroRNA-17/20a inhibits glucocorticoid-induced osteoclast differentiation and function through targeting RANKL expression in osteoblast cells. Bone 68 67-75. (doi:10.1016/j.bone. 2014.08.004)

Shi XE, Li YF, Jia L, Ji HL, Song ZY, Cheng J, Wu GF, Song CC, Zhang QL, Zhu JY et al. 2014b MicroRNA-199a-5p affects porcine preadipocyte proliferation and differentiation. International Journal of Molecular Sciences 15 8526-8538. (doi:10.3390/ijms15058526)

Stahn C \& Buttgereit F 2008 Genomic and nongenomic effects of glucocorticoids. Nature Clinical Practice. Rheumatology 4 525-533. (doi:10.1038/ncprheum0898)

Taipaleenmaki H, Bjerre HL, Chen L, Kauppinen S \& Kassem M 2012 Mechanisms in endocrinology: micro-RNAs: targets for enhancing osteoblast differentiation and bone formation. European Journal of Endocrinology 166 359-371. (doi:10.1530/EJE-11-0646)

Tait AS, Butts CL \& Sternberg EM 2008 The role of glucocorticoids and progestins in inflammatory, autoimmune, and infectious disease. Journal of Leukocyte Biology 84 924-931. (doi:10.1189/jlb.0208104)
Walsh S, Jordan GR, Jefferiss C, Stewart K \& Beresford JN 2001 High concentrations of dexamethasone suppress the proliferation but not the differentiation or further maturation of human osteoblast precursors in vitro: relevance to glucocorticoid-induced osteoporosis. Rheumatology 40 74-83. (doi:10.1093/rheumatology/40.1.74)

Wang Y, Li YP, Paulson C, Shao JZ, Zhang X, Wu M \& Chen W 2014 Wnt and the Wnt signaling pathway in bone development and disease. Frontiers in Bioscience 19 379-407. (doi:10.2741/4214)

Wei J, Shi Y, Zheng L, Zhou B, Inose H, Wang J, Guo XE, Grosschedl R \& Karsenty G 2012 miR-34s inhibit osteoblast proliferation and differentiation in the mouse by targeting SATB2. Journal of cell Biology 197 509-521. (doi:10.1083/jcb.201201057)

Weinstein RS 2001 Glucocorticoid-induced osteoporosis. Reviews in Endocrine \& Metabolic Disorders 2 65-73. (doi:10.1023/ A:1010007108155)

Weinstein RS, Jilka RL, Parfitt AM \& Manolagas SC 1998 Inhibition of osteoblastogenesis and promotion of apoptosis of osteoblasts and osteocytes by glucocorticoids. Potential mechanisms of their deleterious effects on bone. Journal of Clinical Investigation 102 274-282. (doi:10.1172/JCI2799)

Wu D, Huang HJ, He CN \& Wang KY 2013 MicroRNA-199a-3p regulates endometrial cancer cell proliferation by targeting mammalian target of rapamycin (mTOR). International Journal of Gynecological Cancer $\mathbf{2 3}$ 1191-1197. (doi:10.1097/IGC.0b013e31829ea779)

Xing W, Hao L, Yang X, Li F \& Huo H 2014 Glucocorticoids induce apoptosis by inhibiting microRNA cluster miR-17-92 expression in chondrocytic cells. Molecular Medicine Reports 10 881-886. (doi:10.3892/mmr.2014.2253)

Xu Z, Choudhary S, Voznesensky O, Mehrotra M, Woodard M, Hansen M, Herschman H \& Pilbeam C 2006 Overexpression of Cox-2 in human osteosarcoma cells decreases proliferation and increases apoptosis. Cancer Research 66 6657-6664. (doi:10.1158/0008-5472. CAN-05-3624)

Xu N, Zhang J, Shen C, Luo Y, Xia L, Xue F \& Xia Q 2012a Cisplatininduced downregulation of miR-199a-5p increases drug resistance by activating autophagy in HCC cell. Biochemical and Biophysical Research Communications 423 826-831. (doi:10.1016/j.bbrc.2012. 06.048)

Xu N, Zhang L, Meisgen F, Harada M, Heilborn J, Homey B, Grander D, Stahle M, Sonkoly E \& Pivarcsi A 2012b MicroRNA-125b down-regulates matrix metallopeptidase 13 and inhibits cutaneous squamous cell carcinoma cell proliferation, migration, and invasion. Journal of Biological Chemistry 287 29899-29908. (doi:10.1074/jbc.M112.391243)

Yang B, Lin H, Xiao J, Lu Y, Luo X, Li B, Zhang Y, Xu C, Bai Y, Wang H et al. 2007 The muscle-specific microRNA miR-1 regulates cardiac arrhythmogenic potential by targeting GJA1 and KCNJ2. Nature Medicine 13 486-491. (doi:10.1038/nm1569)

Zamore PD \& Haley B 2005 Ribo-gnome: the big world of small RNAs. Science 309 1519-1524. (doi:10.1126/science.1111444)

Zeng Y 2006 Principles of micro-RNA production and maturation. Oncogene 25 6156-6162. (doi:10.1038/sj.onc.1209908)

Received in final form 3 April 2015

Accepted 15 April 2015

Accepted Preprint published online 15 April 2015 http://jme.endocrinology-journals.org DOI: 10.1530/JME-14-0314
() 2015 Society for Endocrinology Printed in Great Britain
Published by Bioscientifica Ltd. 